\title{
Remote Study of Aufeis along the 'Power of Siberia' Gas Pipeline in the Aldan River Basin
}

\author{
Dmitry D. Nogovitsyn, Dmitry D. Pinigin* and Nadezhda A. Nikolaeva \\ Larionov Institute of Physical and Technical Problems of the North SB RAS, 1 Oktyabrskaya, Yakutsk, Russia
}

\begin{abstract}
The 'Power of Siberia' gas pipeline route passes through the territories of South-West and South Yakutia, where the natural conditions are characterized by severe climatic, complex engineering geological and geocryological conditions. A variety of environmental conditions are mandatory for construction and operation in different areas with long-term soil and hazardous geocryological processes: debris flow formation, aufeis formation, soil heaving, thermokarst, thermosuffosion. Aufeis formation processes will be of particular importance during the construction of the pipeline. As a degree of their occurrence in the Republic of Sakha (Yakutia), it should be mentioned the Aldan upland. Aufeis occur almost in the majority of local stream valleys as a small areas of ice formations, basically confined to floodplain and riverbed.

Aufeis areas had been identified in trace areas by the method of deciphering satellite images within the territory of the hydrogeological zones of the Lena-Amur interfluve. As a result of remote studies, territorial and quantitative distributions in hydrogeological zones have been identified. As a result of the monitoring results the areas of each aufeis are determined and their contours are decoded due to satellite images of recent years (2018-2020).
\end{abstract}

\section{Introduction}

One of the priority, economically feasible projects of the present time in the Republic of Sakha (Yakutia) is the implementation in Eastern Siberia of 'Power of Siberia' pipeline, supplying natural gas from the Chayandinskoye oil and gas condensate field to Primorsky Krai and the Asia-Pacific countries.

In the Republic of Sakha (Yakutia), the gas pipeline route has been laid through the territories of South Yakutia within the Olekminsky, Lensky, Neryungri and Aldansky regions.

The natural conditions of the territory along which the main gas pipeline route passes are characterized by severe climatic, complex engineering-geological and geocryological conditions [1]. Various natural conditions of the route cause a number of specific problems, including environmental ones, at the stages of construction and operation within areas with permafrost and hazardous geocryological processes [3].

The main exogenous geological processes that complicate the operating conditions of the gas pipeline are cryogenic processes (kurum formation, aufeis formation, heaving, thermokarst, thermosuffosion), erosion processes; karst-suffusion processes. Aufeis formation processes will be of particular importance during the construction of the gas pipeline.

According to the degree of their manifestation, the Chulman plateau landscape province is distinguished, which belongs to the category of aufeis with a coefficient of relative development from 0.1 to $1 \%$. Aufeis formations are formed practically in most of the valleys of local watercourses in the form of small ice crust formations, confined mainly to their floodplain and riverbed [4]. This site belongs entirely to the Aldan River basin.

The object of the work is a route section of the 'Power of Siberia' pipeline located in the catchment area of the Aldan River. It has a length of $509 \mathrm{~km}$, and is located on the territory of the Aldan and Neryungri regions of the Republic of Sakha (Yakutia), forming a corridor with the ESPO-1 transport system with a width of up to $7.0 \mathrm{~km}$.

Physically and geographically, the main pipeline route in the Aldan River basin runs along the southern edge of the Prilensky plateau, which passes along the gas pipeline to the Aldan Upland at elevations of 700-1000 m above sea level, and further to the northern slope of the Stanovoy Range, with heights of 850-1100 m above sea level.

Thus, the aim of the work is to identify the primary characteristics of aufeis recorded remotely at the

\footnotetext{
${ }^{*}$ Corresponding author: pinigind@mail.ru
} 
crossings of the 'Power of Siberia' pipeline through the watercourses of the Aldan River basin.

\section{Method of work}

The methodological basis of the work is the aerospace method, which consists in fixing aufeis ice massifs on aerospace materials in different seasons.

The use of satellite imagery makes it possible to determine the location and shape of aufeis, their dimensions - width, length, area. The analysis of highresolution satellite images also makes it possible to obtain data on the location, conditions of emergence of aufeisforming sources, to determine the paths and boundaries of water spreading over the aufeis [5].

High resolution color space images of 'Google Maps' service were used in the shell program QGIS 3. Also combinations of different spectra satellite images from spacecraft Sentinel-2 to identify aufeis formation processes and true color images (TCI) for aufeis contours deciphering.

In view of the difficulties in fixing the contours of aufeis in the winter period, the relatively late melting of snow cover and high spring cloud cover rate within the study area, the most qualitative option for interpreting aufeis in 2018-2020 was the interval from the last decade of May to the first decade of June. Thus, the data on the areas of aufeis cover reflect their area during the period of destruction, i.e. dissection into isolated ice massifs, drying, etc. [5]

In this regard, the calculation took into account the remnants of aufeis, representing separately lying ice blocks within a radius of up to $1.0 \mathrm{~km}$ from the pipeline crossing. Moreover, the sum of their areas was designated by the area of aufeis formed during the winter and spring periods of a given year. An example of deciphering aufeis on the river Tit is shown in Fig. 1-2.

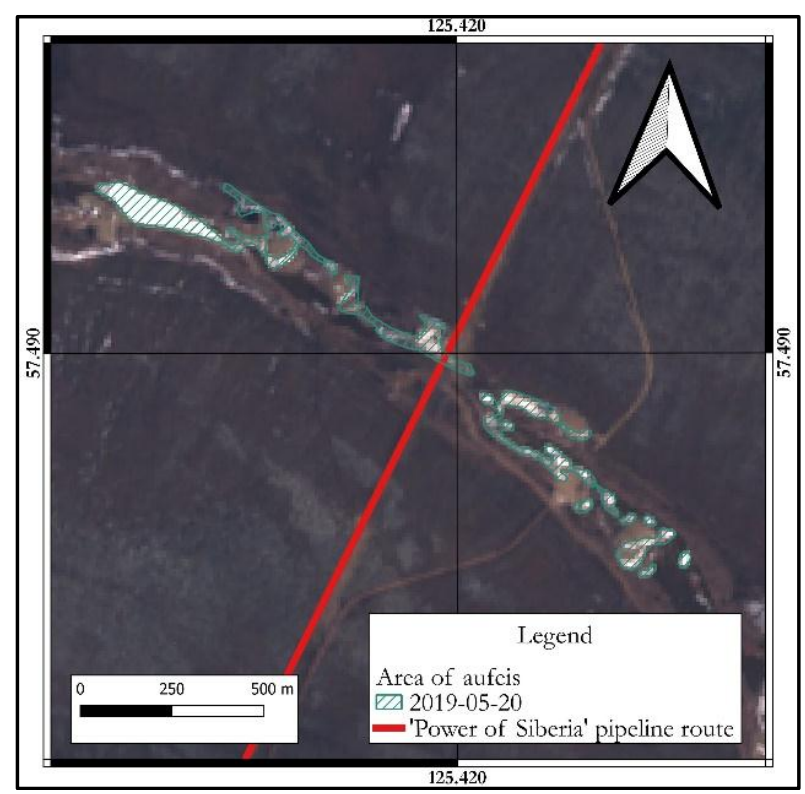

Fig. 1. Ice massifs on the Tit River near the route of the 'Power of Siberia' pipeline (May 20, 2019).

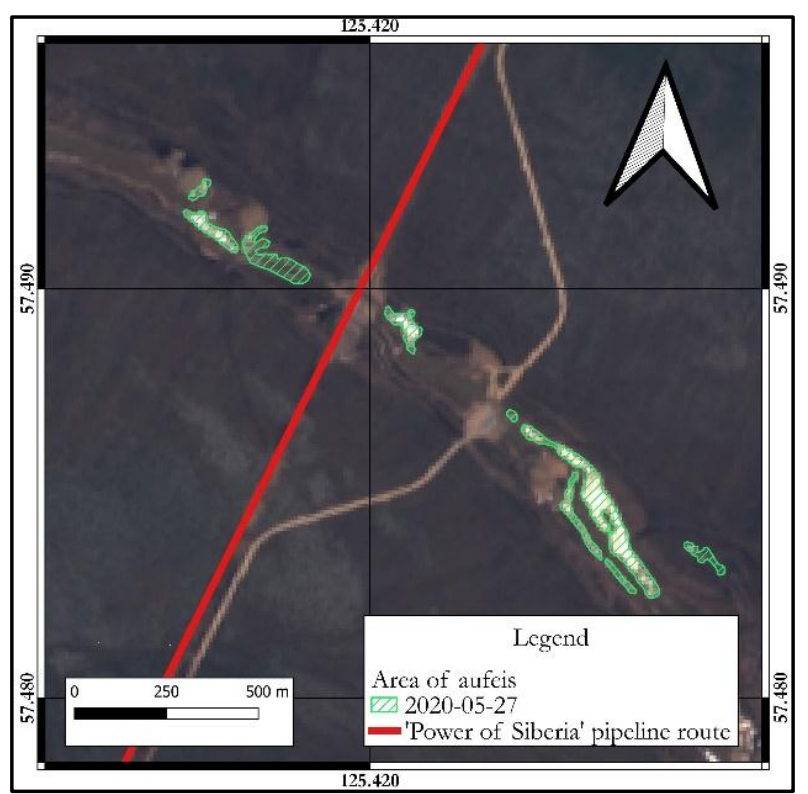

Fig. 2. Ice massifs on the Tit River near the route of the 'Power of Siberia' pipeline (May 27, 2020)

\section{Results and discussion}

As a result of space images analyses of high ('Google Earth' web service) and medium (images by Sentinel-2 spacecraft) resolution for 2018-2020, the contours of 22 aufeis sections, intersected by the 'Power of Siberia' pipeline during the construction and operation period, were deciphered.

The maximum aufeis areas were calculated, thereat it was revealed that some of them were deciphered not each year. A possible reason is either the complete absence of the manifestation of aufeis or its rapid drying due to the significantly lower formed capacities.

The list of the aufeis areas distributed along the gas pipeline with an aufeis area (S) and an area of aufeis within the right-of-way of pipeline route $\left(\mathrm{S}_{\text {row }}\right)$ is shown in Table 1. 
Table 1. Maximum decrypted aufeis area along 'Power of Siberia' pipeline in the Aldan Basin

\begin{tabular}{|l|l|l|l|l|}
\hline № & Stream & Flows into & $\begin{array}{l}\text { S. } \\
\text { ha }\end{array}$ & $\begin{array}{l}\text { Srow. } \\
\text { ha }\end{array}$ \\
\hline 1. & Billyakh & Ollongoro & 2.2 & 1.0 \\
\hline 2. & Lekechekhtakh & Kumakhilakh & 0.2 & 0.07 \\
\hline 3. & Tabornyi & Kumakhilakh & 2.4 & 0.3 \\
\hline 4. & Zvezda & Seligdar & 11.1 & 0 \\
\hline 5. & Krasnyi & Seligdar & 12.3 & 0.6 \\
\hline 6. & Komandirskii & Kerak & 6.6 & 0.4 \\
\hline 7. & $\begin{array}{l}\text { Khangas- } \\
\text { Nipipelineerkan }\end{array}$ & $\begin{array}{l}\text { Bol'shoi } \\
\text { Nimnyr }\end{array}$ & 11.8 & 0.2 \\
\hline 8. & Achchygyi-Legleger & Legleger & 44.6 & 1.1 \\
\hline 9. & Ulakhan-Legleger & Legleger & 8.6 & 0.5 \\
\hline 10. & Tit & Legleger & 1.6 & 0.04 \\
\hline 11. & Erge & Legleger & 40.7 & 0.45 \\
\hline 12. & Malaya Murkugu & Khatymi & 1.4 & 0.55 \\
\hline 13. & Yngyr & Timpton & 2.6 & 0.7 \\
\hline 14. & Chul'makan & Timpton & 21.9 & 0 \\
\hline 15. & Zimovie & Gorbyllakh & 9.4 & 0.05 \\
\hline 16. & Olongro & Gorbyllakh & 2.1 & 0.04 \\
\hline 17. & Untitled stream & Buoyuma & 17.7 & 0.8 \\
\hline 18. & Untitled stream & Ulakhan- & 13.8 & 0.5 \\
\hline 19. & Severikan & Amyranchi & 50.7 & 0.2 \\
\hline 20. & Untitled stream & 0.06 & 0.8 \\
\hline 22. & Untitled stream & & \\
\hline
\end{tabular}

Identification of aufeis annual manifestation in 20182020 remote methods are typical both for significant (more than 40 hectares) in areas and for insignificant (for example, a section of the Tit River with an area of less than 2 hectares) aufeis. Aufeis of a pronounced anthropogenic character were identified on three watercourses (Billyakh, Zimovie and the right tributary of the Timpton River) as well. One of those anthropogenic aufeis on the Billyakh River, first deciphered in images of 2019 is shown in Fig. 3.

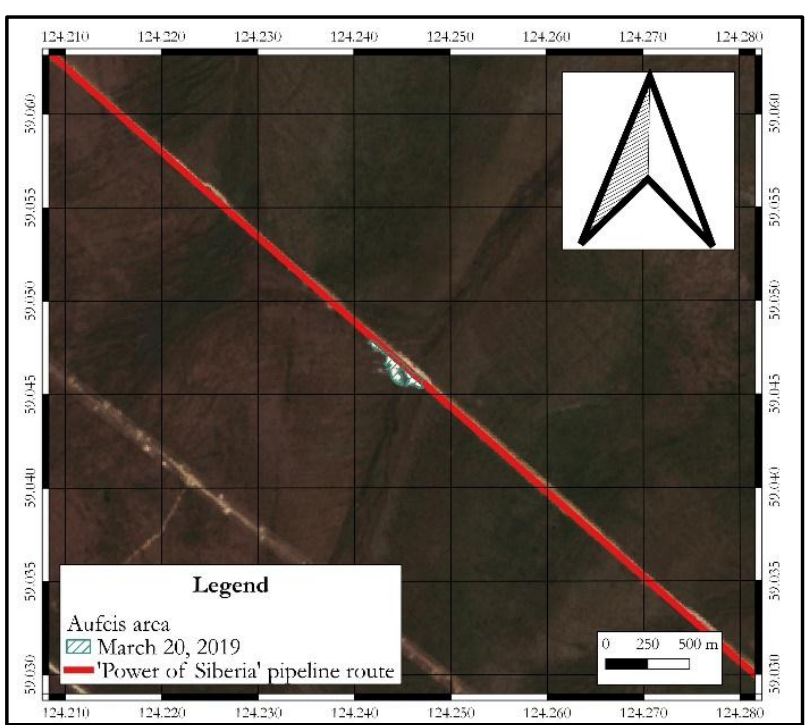

Fig. 3. Billyakh aufeis area on the Sentinel-2 satellite image (date: March 20, 2019)

To fix anthropogenic character of aufeis formation analyses of satellite images by Landsat- 8 spacecraft, taken before the gas pipeline route construction start were conducted, which show no considerable ice massifs deciphered in the aufeis stream reaches (Fig. 4).

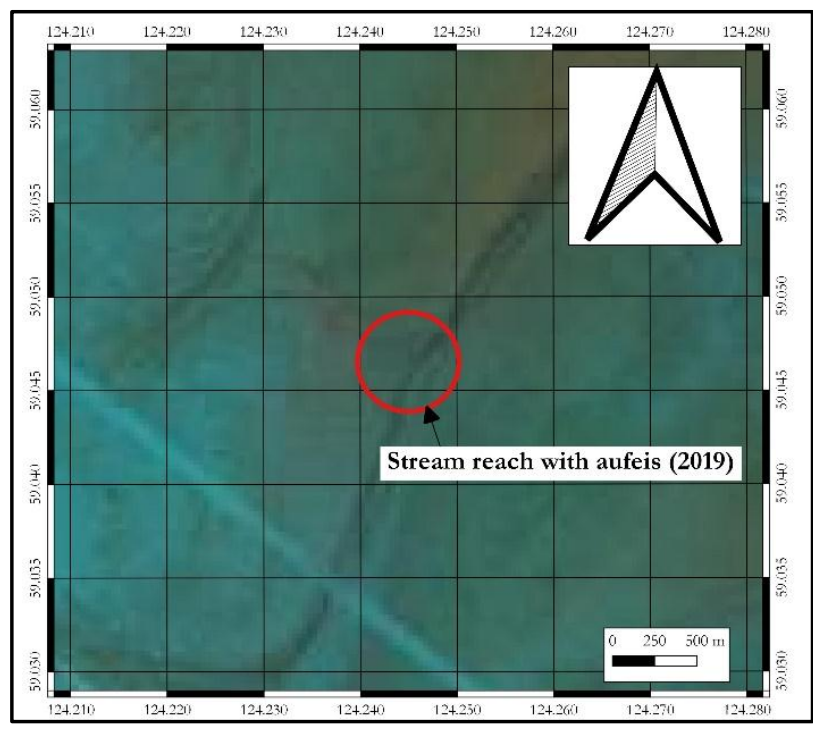

Fig. 4. Billyakh aufeis area before gas pipeline construction on the Landsat- 8 satellite image (date of survey: May 9, 2015)

The development of new aufeis formation is a dangerous phenomenon, as it leads to a change in energy and mass transfer in river valleys, which in turn can affect the exogenous geological processes and water balance of the territory [5].

To determine the confinement of aufeis manifestations to hydrogeological structures, a study of the location of aufeis areas relative to hydrogeological regions was carried out. Zoning of the Lena- Amur interfluve was used [6] in view of the proportionality of the scale of the map schemes and the full coverage of the study area. 
Thus, according to the zoning, the aufeis areas are located within the Yakut complex artesian basin, the Baikal- Dzhugdzhur complex hydrogeological fold area, and artesian basins of the Aldan type [6] (Fig. 5).

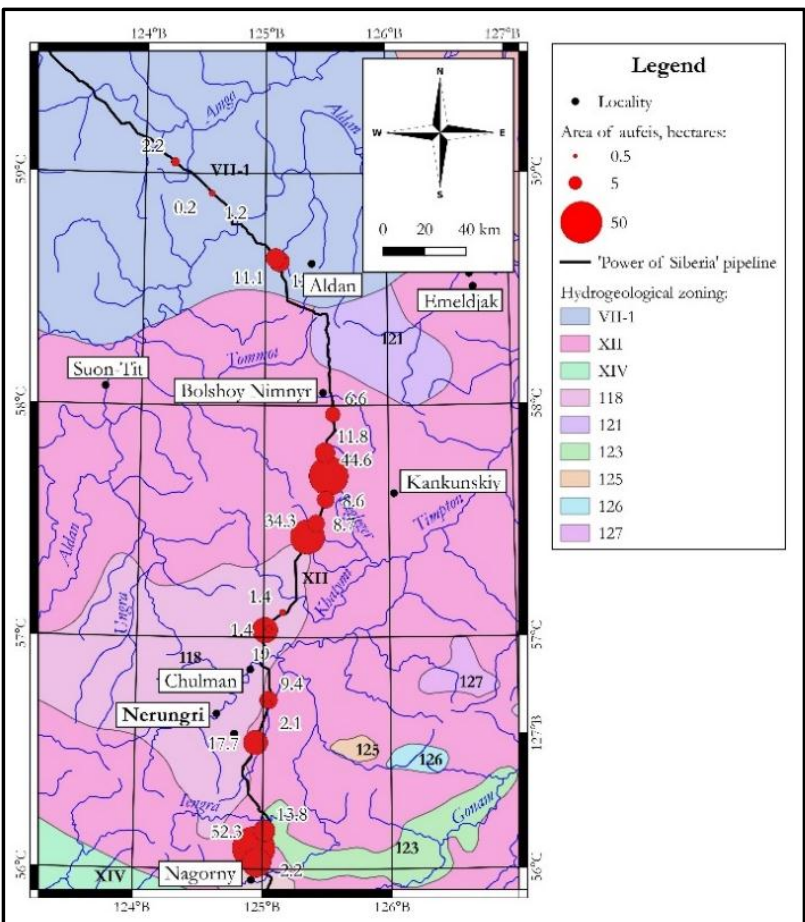

Fig. 5. Schematic map of the hydrogeological zoning of the interpreted aufeis crossed by the 'Power of Siberia' pipeline. Legend: Artesian basins of the second and third orders: VII - Aldan wing of the Yakut artesian basin, VII1 - Tolbinsky; hydrogeological folded areas of the second order: XII - Aldan, XIV - North Dauria; artesian basins of the Aldan type: 118 - Chulmansky, 121 Yukhtino-Ylllymakhsky, 123 - Tokarikano-Iyengrsky, 125 - Mölemkensky, 126 - Guvilgrinsky, 127 Anamzhaksky.

The largest number of deciphered aufeis belongs to the Baikal- Dzhugdzhur complex hydrogeological region of the 1st order, on the territory of which $344.3 \mathrm{~km}$ of the pipeline was laid ( $65.7 \%$ of the studied area), while $77.3 \%$ of the found aufeis are represented here, and in the areal expression - 91.2\%. According to [6] this area is replete with large-scale debit sources; the nature of water manifestations here is directly dependent on tectonic fragmentation and the degree of freezing of rocks.

Among the hydrogeological regions of the 2 nd and $3 \mathrm{rd}$ orders, the Aldan hydrogeological fold area of the 2nd order stands out, occupying approx. $36 \%$ of the route with 11 aufeis with a total decoded area of aufeis $71.0 \%$. The hydrogeological region of the third order - YukhtinoYllymakhsky, where not a single aufeis along the pipeline is represented with the length of the gas pipeline here $34.5 \mathrm{~km}$ (or $6.7 \%$ of the studied part of the main gas pipeline) turned out to be relatively less aufeis hazardous.

\section{Conclusion}

Deciphering the contours of aufeis crossed by the 'Power of Siberia' route within the study area revealed the presence of 22 icy areas with a total area of icy massifs of more than 295 hectares, while the approximate nature of this indicator is noted in view of the difficulties in deciphering aerial photographs of the spring period in the Aldan Highlands.

Aufeis areas of anthropogenic origin were recorded, expressed in new manifestations of aufeis processes in the sections of river crossings of the gas pipeline, where aufeis was not recorded before the start of construction work.

The confinement of aufeis areas to hydrogeological areas has been determined. As a result, a relatively lesser aufeis hazard of the Yukhtino-Ylllymakhsky artesian basin of the Aldan fold area is shown.

\section{References}

1. Kudryavtseva V.A. South Yakutia. Permafrosthydrogeological and engineering geological conditions of the Aldan mining industrial area (MSU publishing, Moscow, 1975)

2. M.M. Schatz, Geoecological problems of the oil and gas industries of Yakutia, Industrial safety and ecology. 10 (43), 36-42 (2009).

3. M.N. Zhelezniak, S.I. Serikov, A.A. Urban and V.N. Semenov, Engineering geocryological and geotechnical conditions of the ESPO pipeline route in section Aldan-Tynda, Science supply of large projects implementation in the Sakha (Yakutia) Republic, 6166 (2009).

4. Zhelezniak M.N., Dorofeev I.V., Serikov S.I., Urban A.A., Semenov V.N. Engineering geocryological conditions of the ESPO pipeline route in the Sakha (Yakutia) Republic (Yakutsk, 2009)

5. Alekseyev V.R. Landscape indication of the aufeis processes (Nauka, Novosibirsk, 2005)

6. Alekseyev V.R. Aufeis of the Lena-Amur Interstream Area, Siberian geographical collection, 10, 46-127 (1975). 